ISSN 1817-7204(Print)

ISSN 1817-7239(Online)

\author{
ЖЫВЁЛАГАДОЎЛЯ І ВЕТЭРЫНАРНАЯ МЕДЫЦЫНА \\ ANIMAL HUSBANDRY AND VETERINARY MEDICINE
}

УДК 636.085.522.2:636.085.7

https://doi.org/10.29235/1817-7204-2021-59-2-205-214

Поступила в редакцию 30.07.2020

Received 30.07.2020

\author{
А.Г. Тулинов, А. Ю. Лобанов \\ Институт агробиотехнологий ФИЦ Коми НЦ УрО РАН, Сыктывкар, Республика Коми, Россия

ОБОСНОВАНИЕ ОСНОВНЫХ КОНСТРУКТИВНО-ТЕХНОЛОГИЧЕСКИХ
ПАРАМЕТРОВ ТЕХНОЛОГИИ ЗАГОТОВКИ СЕНАЖА ИЗ ЕЖИ СБОРНОЙ
(DACTYLIS GLOMERATA L.) С ИСПОЛЬЗОВАНИЕМ ГАЗОВОГО КОНСЕРВАНТА

Аннотация: Важнейшая задача для дальнейшего развития животноводства - увеличение производства кормов, повышение их качества и снижение себестоимости. Важным в этих условиях становится параллельное развитие двух направлений - создание высокопродуктивных агроценозов и развитие технологий, способных полученную кормовую массу сохранить для дальнейшего использование в зимний период. Ценным компонентом в травосмесях при создании высокопродуктивных сенокосов в Северо-Западном регионе является ежа сборная (Dactylis glomerata L.), которая в условиях Севера формирует достаточно высокий урожай кормовой массы, так как хорошо отзывается на внесение удобрений. На базе Института агробиотехнологий ФИЦ Коми НЦ УрО РАН (Россия, Республика Коми, г. Сыктывкар) разработано устройство для обработки сенажа углекислым газом. Для определения эффективности использования данного приема при заготовке сенажа из ежи сборной были проведены две серии опытов - лабораторный и полевой. В ходе лабораторного опыта провели эксперимент по плану Бокса-Бенкена второго порядка для четырех факторов с тремя уровнями варьирования. В результате были определены оптимальные параметры работы устройства: плотность сырья; объем сырья, обрабатываемый одной форсункой; расход газового консерванта и его доза. В полевом опыте провели обработку сенажа в рулонах согласно определенным оптимальным параметрам. Полученный корм сравнили по качеству с сенажом, приготовленным из этого же сырья с соблюдением стандартной технологии, но без применения каких-либо консервантов. В результате исследований установлено, что наиболее эффективно углекислый газ при заготовке ежи сборной в качестве сырья для сенажа действует при следующих параметрах: плотность прессования сенажной массы - 290-330 кг $\mathrm{M}^{3}$; влажность сырья - 53-55 \%; доза вносимого в сенаж углекислого газа $(0,40-0,50) \cdot 10^{-3} \mathrm{M}^{3} /$ кг; расход двуокиси углерода через редуктор подачи газа $-0,50-0,60 \mathrm{~m}^{3} /$ ч. Это обеспечивает повышение сбора кормовых единиц в 1 кг корма на 0,3, обменной энергии - на 0,4 МДж, переваримого протеина - на 1 г. Благодарности. Исследование проведено при финансовой поддержке Министерства образования и науки Российской Федерации в рамках Государственного задания № 0412-2019-0051, рег. № НИОКТР AAAA-A20-120 022 790 009-4.

Ключевые слова: высокопродуктивные сенокосы, травосмеси, заготовка кормов, ежа сборная (Dactylis glomerata L.), сенаж, консерванты, углекислый газ, питательная ценность

Для цитирования: Тулинов, А.Г. Обоснование основных конструктивно-технологических параметров технологии заготовки сенажа из ежи сборной (Dactylis glomerata 1.) с использованием газового консерванта / А. Г. Тулинов, А. Ю. Лобанов // Вес. Нац. акад. навук Беларусі. Сер. аграр. навук. - 2021. - Т. 59, № 2. - С. $205-214$. https://doi.org/10.29235/1817-7204-2021-59-2-205-214

(C) Тулинов А.Г., Лобанов А. Ю., 2021 
Aleksei G. Tulinov, Aleksander Y. Lobanov

Institute of Agrobiotechnology Federal Research Center Komi Scientific Center Ural Branch of the Russian Academy of Sciences, Syktyvkar, Komi Republic, Russia

\title{
SUBSTANTIATION OF THE BASIC CONSTRUCTIVE-AND-TECHNOLOGICAL PARAMETERS OF TECHNOLOGY FOR PREPARING HAYLAGE OF THE COCKSFOOT (DACTYLIS GLOMERATA L.) USING GAS PRESERVATIVE
}

\begin{abstract}
The most important task for the further development of animal breeding is increase of production of feed, increase of its quality and reduction of production costs. Important thing in these conditions is the parallel development of two areas - creation of highly productive agrocenoses and development of technologies capable of saving the obtained feed mass for future use during winter period. A valuable component in grass mixtures when creating highly productive hayfields in the North-West region is the cocksfoot (Dactylis glomerata L.), which in the North conditions forms rather high yield of feed mass, as soon as it responds to fertilizer application properly. On the basis of the Institute of Agrobiotechnology Federal Research Center Komi Scientific Center Ural Branch of the Russian Academy of Sciences (Russia, Komi Republic, Syktyvkar), a device has been developed for treating haylage by carbon dioxide. To determine the efficiency of this technique when harvesting haylage of cocksfoot, two series of experiments were carried out - laboratory and field. In the course of the laboratory experiment, we conducted an experiment according to the Box-Behnken plan of the second order for four factors with three levels of variation. The optimal parameters of the device were determined as a result: density of raw materials; volume of raw material processed by one spray nozzle; gas preservative consumption and its dose. In the field experiment, haylage was processed in rolls according to certain optimal parameters. The feed obtained was compared in terms of quality with haylage prepared of the same raw material in compliance with standard technology, but with no preservatives. As a result of the studies, it has been determined that carbon dioxide is most effective when harvesting the cocksfoot as raw material for haylage, with the following parameters: density of pressing the hay mass $-290-330 \mathrm{~kg} / \mathrm{m}^{3}$; moisture content of raw materials $-53-55 \%$; dose of carbon dioxide introduced into the haylage - $(0.40-0.50) \cdot 10^{-3} \mathrm{~m}^{3} / \mathrm{kg}$; carbon dioxide consumption through a gas supply reducer $0.500 .60 \mathrm{~m}^{3} / \mathrm{h}$. This provides an increase in feed units in one kilogram of feed by 0.3 , exchange energy - by $0.4 \mathrm{MJ}$, digestible protein - by $1 \mathrm{~g}$. Acknowledgements. The research was carried out under the financial support of the Ministry of Science and Higher Education of the Russian Federation within the State assignment N 0412-2019-0051, Reg. N SREDTW AAAA-A20-120 022 $790009-4$.
\end{abstract}

Keywords: highly productive hayfields, grass mixtures, forage preparation, cocksfoot (Dactylis glomerata L.), haylage, preservatives, carbon dioxide, nutritional value

For citation: Tulinov A. G., Lobanov A. Y. Substantiation of the basic constructive-and-technological parameters of technology for preparing haylage of the cocksfoot (Dactylis glomerata L.) using gas preservative. Vestsi Natsyyanal'nay akademii navuk Belarusi. Seryya agrarnykh navuk = Proceedings of the National Academy of Sciences of Belarus. Agrarian series, 2021, vol. 59, no 2, pp. 205-214 (in Russian). https://doi.org/10.29235/1817-7204-2021-59-2-205-214

Введение. Важнейшая задача для дальнейшего развития животноводства - увеличение производства кормов, повышение их качества и снижение себестоимости. Неустойчивые погодные условия в Республике Коми, в свою очередь, создают большие проблемы при заготовке высококачественного корма для крупного рогатого скота. Частые дожди в период оптимального укоса травы на корм не позволяют просушить ее до необходимой для сенажа влажности, а ведь именно сенаж является наиболее оптимальным кормом для молочного стада, обеспечивающим его всем необходимым [1]. Важным в этих условиях становится параллельное развитие двух направлений - создание высокопродуктивных агроценозов [2-4] и развитие технологий, способных полученную кормовую массу сохранить для дальнейшего использование в зимний период $[5,6]$.

Ценным компонентом в травосмесях при создании высокопродуктивных сенокосов в СевероЗападном регионе является ежа сборная (Dactylis glomerata L.) - многолетнее кормовое злаковое растение $[7,8]$. Ежа сборная в условиях Севера формирует достаточно высокий урожай кормовой массы [9-11], так как хорошо отзывается на внесение удобрений [12-15]. Ежа сборная является наиболее ценным и пригодным растением для хозяйственного использования. В среднем в первые десять лет средняя урожайность сухой массы составляет 12,3 т/га [16]. Многочисленные исследования подтверждают целесообразность использования ежи сборной в качестве кормовой культуры при заготовке сенажа [17-19].

На базе Института агробиотехнологий ФИЦ Коми НЦ УрО РАН (г. Сыктывкар, Республика Коми, Россия) разработано устройство для обработки сенажа углекислым газом ${ }^{1}$. Данное устройство обеспечивает равномерную подачу газового консерванта (углекислого газа) в прессованную

\footnotetext{
${ }^{1}$ Мобильный комплекс для создания анаэробной среды в сенаже : пат. RU 2555435 / А.Ю. Лобанов, А. Ф. Триандафилов. Опубл. 10.07.2015.
} 
сенажную массу. Для этого устройство снабжено источником жидкой углекислоты, которая через распределительный редуктор с определенным расходом подается через стальную штангу. Предварительно введенная в обмотанный в полимерную пленку рулон сенажа штанга обеспечивает равномерную непрерывную подачу углекислого газа, который за счет своего молекулярного веса вытесняет кислород воздуха из травяного сырья. Изначально его количество в сенаже весьма велико, что позволяет аэробной микрофлоре активно вести жизнедеятельность, на которую расходуется питательная ценность корма, происходит накопление различных кислот. Аэробная фаза может протекать от 3 до 5 дней. Удаление кислорода из сенажа приводит к моментальному переходу от аэробной фазы к анаэробной. Это позволяет сократить расход углеводов и снизить температуру заложенной на хранение массы [20].

Цель настоящей работы - обоснование основных конструктивно-технологических параметров технологии заготовки сенажа из ежи сборной (Dactylis glomerata 1.) с использованием газового консерванта.

Материалы и методы исследования. На базе Института агробиотехнологий ФИЦ Коми НЦ УрО РАН (г. Сыктывкар, Республика Коми, Россия) разработано устройство для обработки сенажа углекислым газом. Для определения эффективности использования данного приема при заготовке сенажа из ежи сборной были проведены две серии опытов - лабораторный и полевой.

Исследования проводили в соответствии с планом четырехфакторного эксперимента второго порядка Бокса-Бенкена, где функцией отклика принята температура саморазогрева корма $Y_{1}$ $\left(t,{ }^{\circ} \mathrm{C}\right)$, содержание протеина $Y_{2}(\%)$, кормовых единиц $Y_{3}$ (ед/кг). Факторы и уровни варьирования представлены в табл. 1. Уровни варьирования факторов определяли согласно теоретическим расчетам скважности травяного сырья [21]. Было поставлено 27 опытов в трехкратной повторности. В качестве контроля произвели закладку опыта по стандартной технологии (плотность

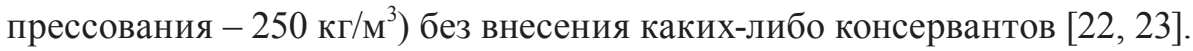

Т а б л и ц а 1. Факторы, их уровни и интервалы варьирования

$\mathrm{T}$ a $\mathrm{b} 1 \mathrm{e} \quad 1$. Factors, their levels and ranges of variation

\begin{tabular}{|c|c|c|c|c|}
\hline \multirow{2}{*}{$\begin{array}{c}\text { Кодированное } \\
\text { обозначение } \\
\text { фактора }\end{array}$} & \multirow[b]{2}{*}{ Фактор } & \multicolumn{3}{|c|}{ Уровень фактора } \\
\hline & & $\begin{array}{c}\text { нижний } \\
(-1)\end{array}$ & $\begin{array}{c}\text { основной } \\
\text { (0) }\end{array}$ & $\begin{array}{c}\text { верхний } \\
(+1)\end{array}$ \\
\hline$x_{1}$ & Плотность прессования $p$ сенажной массы, кг/м³ & 250 & 300 & 350 \\
\hline$x_{2}$ & Доза внесения консерванта $q, 10^{-3} \mathrm{M}^{3} / \kappa \Gamma$ & 0,30 & 0,45 & 0,60 \\
\hline$x_{3}$ & Объем сенажной массы в зоне обработки одного распылителя $Q, 10^{-3} \mathrm{~m}^{3}$ & 48 & 96 & 144 \\
\hline$x_{4}$ & Расход газа $V_{0}$ газа, м³ $/$ ч & 0,30 & 0,50 & 0,70 \\
\hline
\end{tabular}

Схема устройства для проведения лабораторного эксперимента представлена на рис. 1 и состоит из баллона 1 с углекислым газом объемом 40 л с запорным вентилем 2 , к которому подключен редуктор 3 с расходомером. К редуктору с помощью гибкого шланга 4 с внутренним диаметром 6 мм подсоединена штанга 5 , на конце которой закреплен распылитель из нержавеющей стали. Распылитель погружается в середину навески травяной массы 7 , запрессованной в высокопрочном большеобъемном пленочном мешке 7 , снабженным закрывающейся герметично горловиной. После введения консерванта устанавливается термометр 6, и мешок герметизируется.

Для исследований использовали травяное сырье из ежи сборной сорта Нева влажностью 5355 \% с длиной резки 50-70 мм, убранную в период выхода в трубку - колошение [24]².

Введение консерванта контролировали с помощью расходомера, установленного на газовом редукторе. За изменением температуры наблюдали в течение 5 дней после консервирования. Температура саморазогрева не должна превышать $37-38{ }^{\circ} \mathrm{C}$, в противном случае исследуемый вариант выбраковывался.

Математическую обработку результатов проводили в программе STATGRAPHICS Plus 5.0.

\footnotetext{
${ }^{2}$ Методические указания по селекции многолетних злаковых трав / В.М. Косолапов [и др.] ; Всерос. науч.-исслед. ин-т кормов. М. : Изд-во РГАУ - МСХА, 2012. 51 с.
} 


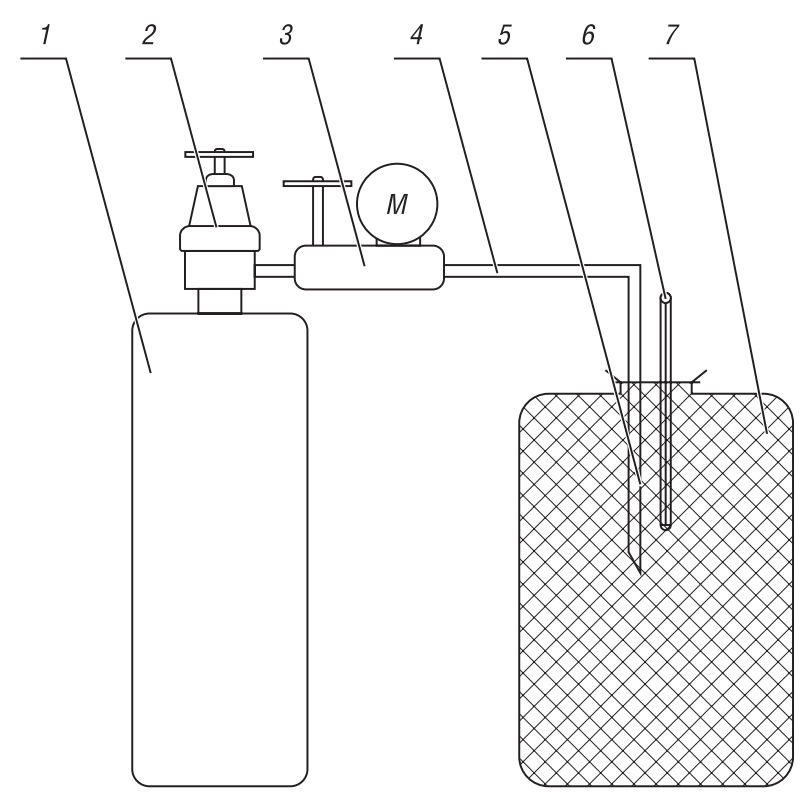

Рис. 1. Схема лабораторного устройства: 1 - газовый баллон; 2 - вентиль; 3 - редуктор; 4 - гибкий шланг; 5 - штанга с распылителем; 6-термометр; 7 - травяная масса в герметичной упаковке

Fig. 1. Scheme of laboratory device: 1 - gas cylinder; 2 valve; 3 - reducer; 4 - a flexible hose; 5 - rod with a spray;

6 - thermometer; 7 - herbal mass in sealed packaging
После определения оптимальных параметров по заготовке сенажа из ежи сборной был проведен полевой опыт с использованием данных параметров. Сенаж, заготовленный по технологии рулонных рукавов с плотностью прессования 300 кг/м³

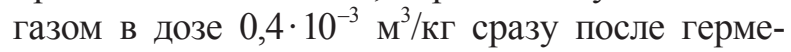
тизации травяной массы полимерной пленкой. Обработку производили одним распылителем с расходом $0,55 \mathrm{~m}^{3} /$ ч. Отбор проб проводили по методике через три месяца после закладки [25].

Результаты и их обсуждение. Получена следующая модель регрессии влияния исследуемых факторов на температуру саморазогрева корма $\left(T,{ }^{\circ} \mathrm{C}\right)$, содержание протеина (\%) и кормовых единиц (ед/кг) $\left(Y_{1}, Y_{2}, Y_{3}\right)$, проверенная на адекватность по $F$-критерию Фишера (вероятность $p=0,95), R_{2}=96,9 \%$ :

$$
\begin{gathered}
Y_{1}=96,2604-0,4008 x_{1}+32,9167 x_{2}+20,8333 x_{3}+ \\
2,9166 x_{4}+0,0005 x_{1}^{2}-51,3889 x_{2}^{2} \\
Y_{2}=3,7699+0,0308 x_{1}+7,5555 x_{2}-42,7951 x_{3}- \\
8,6250 x_{4}+59,8958 x_{3}^{2} \\
Y_{3}=0,0692+0,0029 x_{1}+3,8069 x_{2}-0,7118 x_{3}- \\
3,9296 x_{4}-3,2175 x_{2}^{2}+3,22838 x_{4}^{2} .
\end{gathered}
$$

Изучение уравнений регрессии и двумерных сечений поверхностей отклика позволило установить следующие закономерности влияния изучаемых факторов на температуру саморазогрева $\left(Y_{1},{ }^{\circ} \mathrm{C}\right)$ травяной массы:

- плотность прессования оказывает значительное влияние на температуру саморазогрева сенажа (рис. 2, b). При закладке травяной массы с плотностью 290-310 кг/м ${ }^{3}$ и обработке минимальной дозой консерванта температура не поднималась выше $31{ }^{\circ} \mathrm{C}$. Увеличение плотности прессования более 350 кг/м $\mathrm{M}^{3}$ позволяет полностью отказаться от применения консервантов, что согласуется с исследованиями многих авторов. Однако достижение такой плотности прессования во всем объеме сенажа весьма проблематично;

- внесение 0,39 м³/кг углекислого газа в сенаж (рис. 2, b) позволило удержать температуру саморазогрева травяной массы на приемлемом уровне $35^{\circ} \mathrm{C}$ при наименьшей плотности прессования 250 кг/ ${ }^{3}$;

- повышение дозы до 0,49-0,59 м³/кг при плотности прессования 270-310 кг/м обеспечивает созревание сенажа без саморазогрева. Температура в данных вариантах варьировалась в пределах 20-30 ${ }^{\circ} \mathrm{C}$, что практически не отличается от внешних условий среды. Таким образом, можно сделать вывод, что применение данной дозы консерванта обеспечивает необходимый уровень подавления процессов брожения;

- разница температуры саморазогрева травяной массы между вариантом с максимальной дозой консерванта при минимальной плотности $\left(0,6 \mathrm{~m}^{3} / \kappa г, 250\right.$ кг/м ${ }^{3}$ соответственно) и мини-

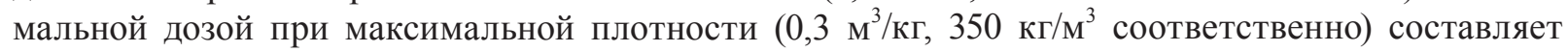
$7^{\circ} \mathrm{C}\left(29\right.$ и $22{ }^{\circ} \mathrm{C}$ соответственно);

- при увеличении объема обрабатываемого материала при сохранении места введения консерванта в одной точке в три раза (рис. 2, c) температура саморазогрева травяного сырья повышалась всего на $2^{\circ} \mathrm{C}$, что говорит о достаточной скорости диффузии газового консерванта внутри травяного сырья и ингибирования процессов жизнедеятельности микроорганизмов;

- увеличение расхода углекислого газа в сенажную массу с 0,3 до 0,7 м³/ч увеличивает температуру саморазогрева на $2^{\circ} \mathrm{C}$. Это связано с пористой структурой сенажной массы, внутри которой имеется запас кислорода, вытесняемого углекислым газом. Увеличение расхода приводит 
к нарушению равномерности распределения углекислого газа в сенажной массе, в результате чего остается невытесненный кислород, используемый микроорганизмами для жизнедеятельности. Данная жизнедеятельность приводит к повышению температуры сенажа;

- не установлено значимого влияния воздействия объема сенажной массы в зоне обработки одного распылителя $(Q)$ и расхода газа $\left(V_{0}\right)$ на температуру саморазогрева сырья по сравнению с влиянием таких факторов, как плотность прессования $(p)$ и доза консерванта (q) при атмосферном давлении.

Изучение уравнений регрессии и двумерных сечений поверхностей отклика позволило установить следующие закономерности влияния изучаемых факторов на содержание протеина $\left(Y_{2}, \%\right)$ в готовом сенаже:

- при анализе уравнений регрессии наблюдали линейную зависимость между всеми исследуемыми факторами. При этом содержание протеина прямо пропорционально плотности прессования и дозе консерванта и обратно пропорционально расходу консерванта и массе обрабатываемой одной форсункой;

- увеличение дозы консерванта (рис. 3, a) на $0,1 \mathrm{~m}^{3} /$ кг в среднем позволяет сохранить на 1,2 \% протеина в сенажной массе;

- наиболее интенсивное влияние увеличения дозы консерванта на сохранность протеина наблюдали в промежутке 0,39-0,59 м³/кг при увеличении плотности прессования от 270 до $310 \kappa г / \mathrm{M}^{3}$;

- наиболее значимое влияние на содержание протеина в сенажной массе (рис. $3, b$ ) оказывает плотность прессования в пределах 250-310 кг/м ${ }^{3}$. При этом содержание протеина повышается от 7,8 до 9,7 \%. При прессовании

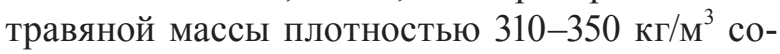
держание протеина составляет 9,7-10,9 \%;

- в среднем увеличение дозы консерванта на $0,03 \mathrm{~m}^{3} /$ кг позволяет обеспечить повышение сохранности протеина на 0,2 \% (рис. $3, c$ );

- разница в содержании протеина в корме между вариантом с максимальной дозой консерванта при минимальной плотности $\left(0,6 \mathrm{~m}^{3} / \kappa г, 250 \mathrm{\kappa r} / \mathrm{M}^{3}\right.$ соответственно) и минимальной дозой при максимальной плотности

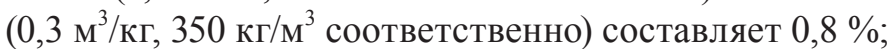

- увеличение объема травяного сырья на $1 \cdot 10^{-2} \mathrm{~m}^{3}$, обрабатываемого одной форсункой, приводит к снижению содержания протеина в корме на 0,3 \%, а снижение расхода углекислого газа

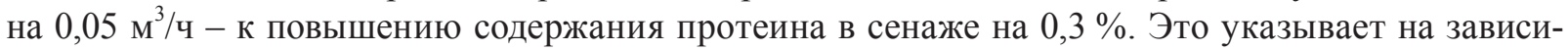
мость качества диффузии углекислого газа от обрабатываемого объема и равномерности его распределения в травяной массе при внесении.
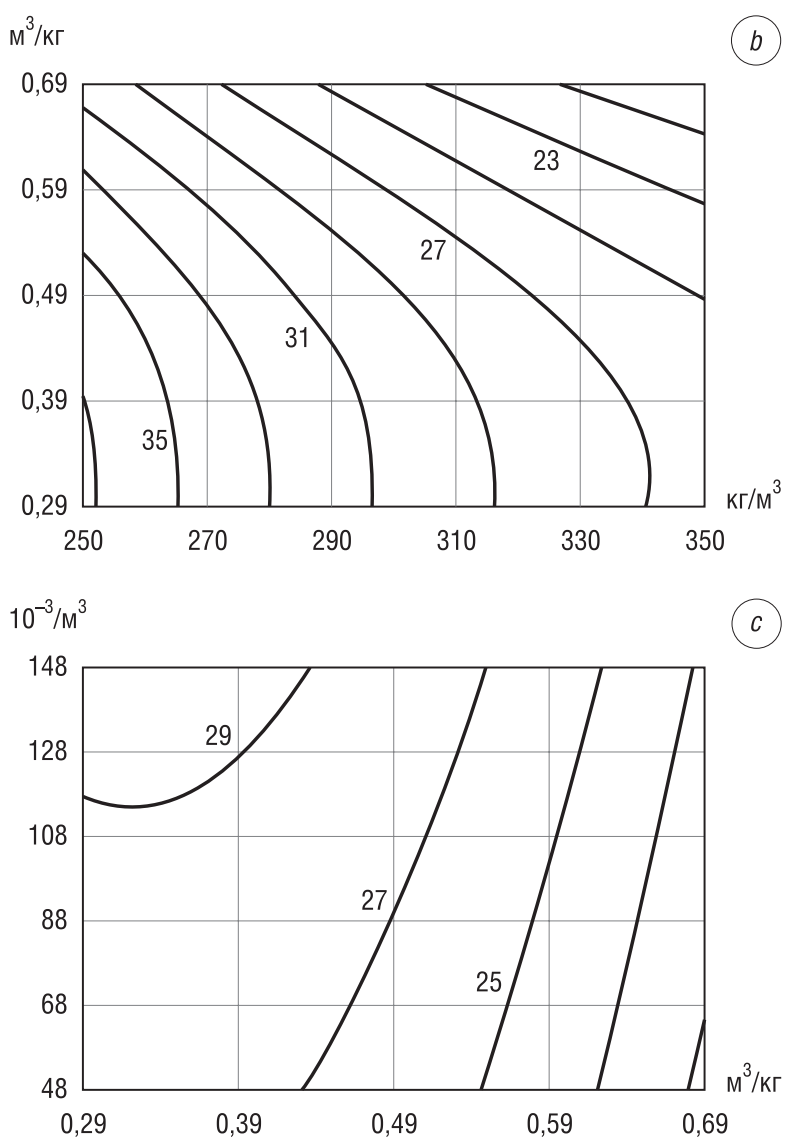

Рис. 2. Двумерные сечения поверхности отклика температуры саморазогрева сенажа $Y_{1}\left(T,{ }^{\circ} \mathrm{C}\right)$ : a) $p\left(x_{1}\right)=$ $300 \mathrm{\kappa г} / \mathrm{m}^{3} ; Q\left(x_{3}\right)=0,096 \mathrm{~m}^{3} ;$ b) $Q\left(x_{3}\right)=0,096 \mathrm{~m}^{3} ; V_{0}\left(x_{4}\right)=$ $0,5 \mathrm{~m}^{3} / \mathrm{ч}$; c) $p\left(x_{1}\right)=300 \mathrm{\kappa г} / \mathrm{m}^{3} ; V_{0}\left(x_{4}\right)=0,5 \mathrm{~m}^{3} / \mathrm{ч}$

Fig. 2. Two-dimensional cross-sections of the response surfaces of the self-heating temperature of haylage $Y_{1}\left(T,{ }^{\circ} \mathrm{C}\right)$ : a) $p\left(x_{1}\right)=300 \mathrm{~kg} / \mathrm{m}^{3} ; Q\left(x_{3}\right)=0,096 \mathrm{~m}^{3}$; b) $Q\left(x_{3}\right)=0,096 \mathrm{~m}^{3}$; $\left.V 0\left(x_{4}\right)=0,5 \mathrm{~m}^{3} / \mathrm{h} ; \mathrm{c}\right) p\left(x_{1}\right)=300 \mathrm{~kg} / \mathrm{m}^{3} ; V_{0}\left(x_{4}\right)=0,5 \mathrm{~m}^{3} / \mathrm{h}$

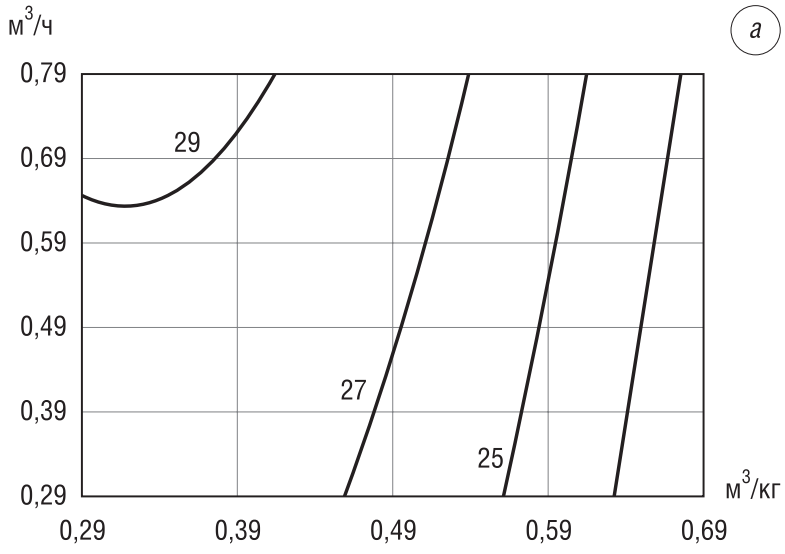




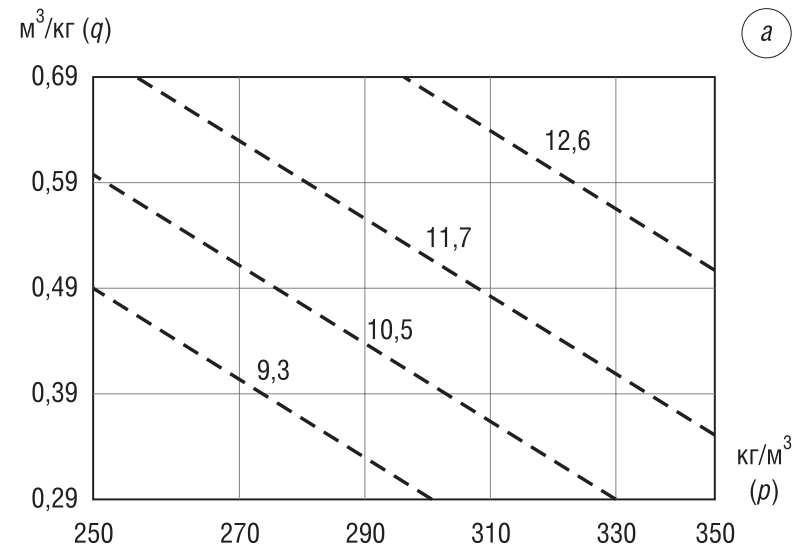

$\mathrm{M}^{3} / 4\left(V_{0}\right)$

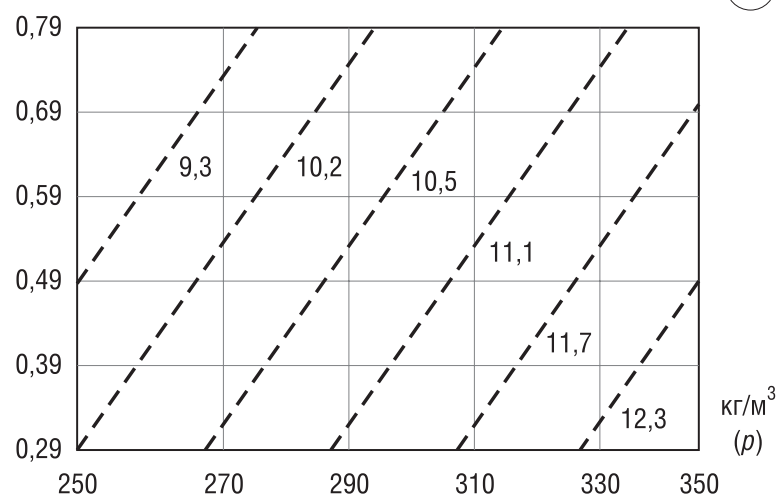

$10^{-3} / \mathrm{M}^{3}(Q)$

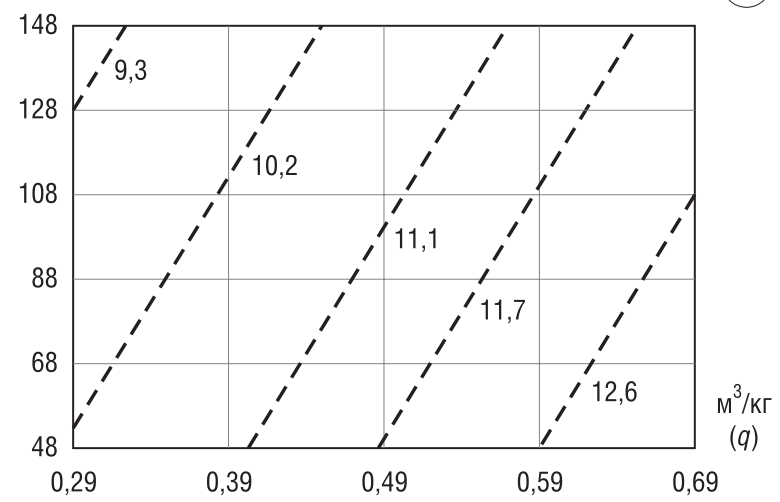

Рис. 3. Двумерные сечения поверхностей отклика содержания протеина сенажа $Y_{2}(\%)$ : a) $Q\left(x_{3}\right)=0,096 \mathrm{~m}^{3} ; V_{0}\left(x_{4}\right)=$ $0,5 \mathrm{~m}^{3} / \mathrm{ч}$; b) $p\left(x_{1}\right)=300 \mathrm{\kappa} \Gamma / \mathrm{m}^{3} ; Q\left(x_{3}\right)=0,096 \mathrm{~m}^{3}$; c) $p\left(x_{1}\right)=$ $300 \mathrm{\kappa} / \mathrm{M}^{3} ; V_{0}\left(x_{4}\right)=0,5 \mathrm{~m}^{3} / \mathrm{ч}$

Fig. 3. Two-dimensional cross-sections of the response surfaces of the protein content of haylage $Y_{2}(\%)$ : a) $Q\left(x_{3}\right)=$ $0,096 \mathrm{~m}^{3} ; V_{0}\left(x_{4}\right)=0,5 \mathrm{~m}^{3} / \mathrm{h}$; b) $p\left(x_{1}\right)=300 \mathrm{~kg} / \mathrm{m}^{3} ; Q\left(x_{3}\right)=$ $0,096 \mathrm{~m}^{3}$; c) $p\left(x_{1}\right)=300 \mathrm{~kg} / \mathrm{m}^{3} ; V_{0}\left(x_{4}\right)=0,5 \mathrm{~m}^{3} / \mathrm{h}$
Изучение уравнений регрессии и двумерных сечений поверхностей отклика позволило установить следующие закономерности влияния изучаемых факторов на содержание кормовых единиц $\left(Y_{3}\right.$, ед/кг) в готовом сенаже:

1) установлено незначительное влияние объема материала, обрабатываемого одной форсункой (рис. 4 a). Так, снижение объема подаваемого газа с $128 \cdot 10^{-3}$ до $68 \cdot 10^{-3} \mathrm{M}^{3}$ при расходе $0,59 \mathrm{~m}^{3} /$ ч позволило увеличить сбор кормовых единиц всего на 0,04 ед/кг. Аналогичный результат наблюдали при снижении объема с $148 \cdot 10^{-3}$ до $88 \cdot 10^{-3} \mathrm{M}^{3}$ при дозе консерванта $0,59 \mathrm{~m}^{3} / \mathrm{ч}$;

2) повышение плотности прессования на 20 кг/м ${ }^{3}$ при неизменных прочих факторах в среднем обеспечило повышение сбора кормовых единиц на 0,07 ед/кг (рис. 4, b);

3) увеличение массовой дозы консерванта от 0,29 до $0,49 \mathrm{~m}^{3} /$ кг обеспечило повышение сбора кормовых единиц на 0,24 ед/кг. Дальнейшее увеличение дозы оказало незначительное влияние на сохранность кормовых единиц в сенаже (рис. 4, c);

4) оптимальный расход углекислого газа составил 0,39-0,59 м³/ч. При данном расходе можно обеспечить максимальный сбор кормовых единиц (рис. 4, a);

5) применение углекислого газа в дозе $0,59 \mathrm{~m}^{3} / \kappa г$ позволяет максимизировать сбор кормовых единиц в точке внесения углекислого газа в сенажную массу. Увеличение обрабатываемого объема на $60 \cdot 10^{-3} \mathrm{M}^{3}$ приводит к постепенному снижению сбора кормовых единиц на 0,04 (рис. 4, c).

Таким образом, в результате исследования моделей регрессии влияния исследуемых факторов (плотность прессования $p$ сенажной массы, кг $/ \mathrm{m}^{3}$; доза внесения консерванта $q, 10^{-3} \mathrm{~m}^{3} /$ кг при атмосферном давлении; объем сенажной массы в зоне обработки одного распылителя $Q, \mathrm{~m}^{3}$; расход газа $V_{0}$ газа, $\mathrm{m}^{3} /$ ч) на температуру саморазогрева корма $\left(T,{ }^{\circ} \mathrm{C}\right)$, содержание протеина (\%) и кормовых единиц (ед/кг) установлено, что наиболее эффективно углекислый газ действует при заготовке сенажа из ежи сборной плотностью 290-330 кг/м ${ }^{3}$ в дозе $(0,40-0,50) \cdot 10^{-3} \mathrm{~m}^{3} /$ кг. Расход в дозе $0,50-0,60 \mathrm{~m}^{3} /$ ч обеспечивает достаточную равномерность распределения углекислого газа в сенаже объемом до $1 \mathrm{~m}^{3}$.

Сенаж из ежи сборной обработали согласно определенным оптимальным параметрам в ходе полевого эксперимента. Результаты данного эксперимента отображены в табл. 2.

Анализ табл. 2 показал, что применение углекислого газа при заготовке сенажа из ежи сборной благоприятно влияет на повышение качества корма. Так, содержание кормовых единиц в 1 кг корма - на 0,3, обменной энергии на 0,4 МДж, переваримого протеина - на 1 г. 

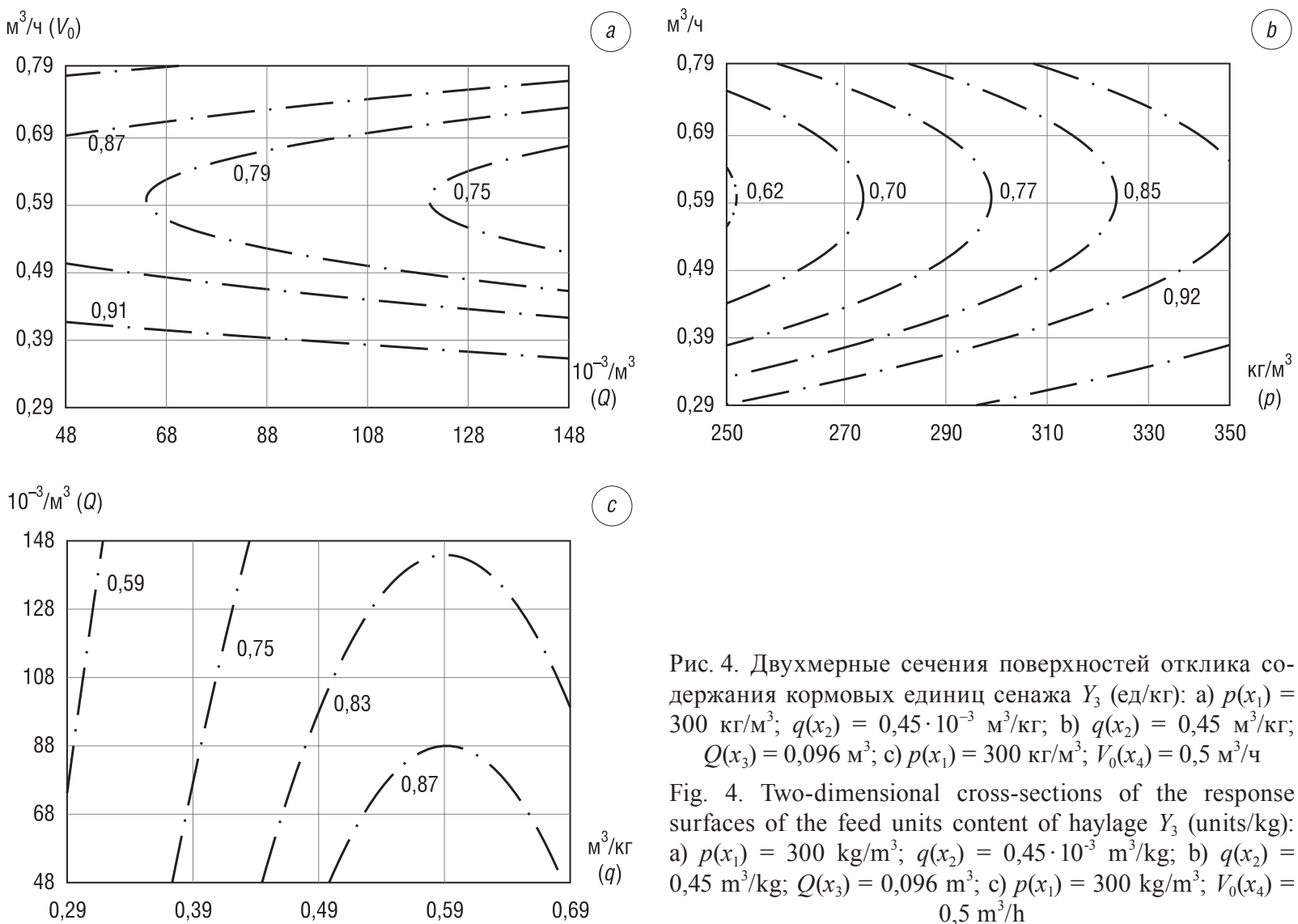

Рис. 4. Двухмерные сечения поверхностей отклика содержания кормовых единиц сенажа $Y_{3}$ (ед/кг): а) $p\left(x_{1}\right)=$ $300 \kappa \Gamma / \mathrm{m}^{3} ; q\left(x_{2}\right)=0,45 \cdot 10^{-3} \mathrm{~m}^{3} / \kappa \Gamma ;$ b) $q\left(x_{2}\right)=0,45 \mathrm{~m}^{3} / \kappa г$; $Q\left(x_{3}\right)=0,096 \mathrm{~m}^{3} ;$ c) $p\left(x_{1}\right)=300 \mathrm{\kappa} \Gamma / \mathrm{m}^{3} ; V_{0}\left(x_{4}\right)=0,5 \mathrm{~m}^{3} / \mathrm{ч}$

Fig. 4. Two-dimensional cross-sections of the response surfaces of the feed units content of haylage $Y_{3}$ (units $/ \mathrm{kg}$ ): a) $p\left(x_{1}\right)=300 \mathrm{~kg} / \mathrm{m}^{3} ; q\left(x_{2}\right)=0,45 \cdot 10^{-3} \mathrm{~m}^{3} / \mathrm{kg} ;$ b) $q\left(x_{2}\right)=$ $\left.0,45 \mathrm{~m}^{3} / \mathrm{kg} ; Q\left(x_{3}\right)=0,096 \mathrm{~m}^{3} ; \mathrm{c}\right) p\left(x_{1}\right)=300 \mathrm{~kg} / \mathrm{m}^{3} ; V_{0}\left(x_{4}\right)=$ $0,5 \mathrm{~m}^{3} / \mathrm{h}$

Т а б л и ц а 2. Результаты полевых испытаний заготовки сенажа из ежи сборной с применением углекислого газа

$\mathrm{T} \mathrm{a} \mathrm{b} 1$ e 2. The results of field tests of harvesting haylage from cocksfoot with using carbon dioxide

\begin{tabular}{|l|c|c|c|c|c|c|c|}
\hline \multirow{2}{*}{ Вариант опыта } & \multicolumn{3}{|c|}{ Химический состав, \%. } & \multicolumn{3}{c|}{ Содержание в 1 кг корма. } \\
\cline { 2 - 9 } & $\begin{array}{c}\text { Сырой } \\
\text { протеин }\end{array}$ & $\begin{array}{c}\text { Сырая } \\
\text { клет- } \\
\text { чатка }\end{array}$ & $\begin{array}{c}\text { Сырая } \\
\text { зола }\end{array}$ & $\begin{array}{c}\text { Сырой } \\
\text { жир }\end{array}$ & $\begin{array}{c}\text { Кормовые } \\
\text { единицы }\end{array}$ & $\begin{array}{c}\text { Обменная } \\
\text { энергия, } \\
\text { МДж }\end{array}$ & $\begin{array}{c}\text { Перевари- } \\
\text { мый } \\
\text { протеин, г }\end{array}$ \\
\hline Базовая технология & 8,3 & 26,8 & 2,6 & 2,3 & 0,29 & 5,9 & 18 \\
\hline Разработанная технология & 9,6 & 24,5 & 2,9 & 2,2 & 0,32 & 6,3 & 19 \\
\hline
\end{tabular}

Заключение. Таким образом, исследования показали, что наиболее эффективно углекислый газ при заготовке ежи сборной в качестве сырья для сенажа действует при следующих пара-

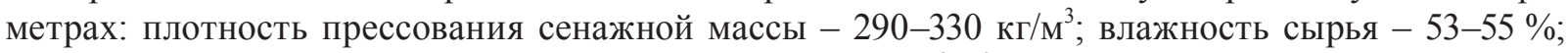

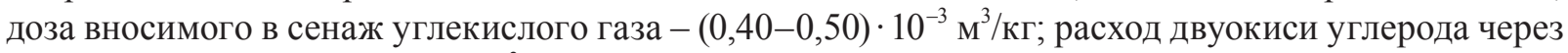
редуктор подачи $-0,50-0,60 \mathrm{~m}^{3} /$. Это обеспечивает повышение сбора кормовых единиц в 1 кг корма на 0,3 , обменной энергии - на 0,4 МДж, переваримого протеина - на 1 г.

Благодарности. Исследование проводилось при финансовой поддержке Министерства образования и науки Российской Федерации в рамках Государственного задания № 0412-2019-0051, рег. № НИОКТР АААА-А20-120022790009-4.

\section{Список использованных источников}

1. Хохрин, С. Н. Микробиологические основы консервирования зеленых кормов / С. Н. Хохрин. - СПб. : Проспект Науки, 2017. - 190 c.

2. Стружкина, T.M. Селекционная ценность зарубежных образцов ежи сборной / Т.М. Стружкина // Кормопроизводство. - 2009. - №6. - С. 22-25. 
3. Наумова, Т.В. Результаты оценки коллекционных образцов ежи сборной в условиях Приморского края / Т. В. Наумова, А. Н. Емельянов // Вестн. Алт. гос. аграр. ун-та. - 2015. - № 8 (130). - С. 22-27.

4. Чувилина, В.А. Преимущества хозяйственно полезных признаков селекционного номера ежи сборной CH-1/2 в предварительном сортоиспытании / В. А. Чувилина // Кормопроизводство. - 2018. - № 11. - С. $38-41$.

5. Триандафилов, А. Ф. Способы и технические средства повышения эффективности обработки сена химическими консервантами : дис. ...канд. тех. наук : 05.20.01 / А. Ф. Триандафилов. - Л. ; Пушкин, 1986. - 156 л.

6. Лобанов, А. Ю. Режимы и параметры технологии обработки сенажа углекислым газом в условиях Республики Коми / А. Ю. Лобанов, А. Ф. Триандафилов // Аграр. наука Евро-Северо-Востока. - 2016. - № 4 (53). - С. 75-80. https:// doi.org/10.30766/2072-9081.2016.53.4.75-80

7. Зверева, Г. К. Использование ежи сборной при улучшении естественных деградированных пастбищ лесостепи / Г. К. Зверева, Е. В. Боголюбова // Кормопроизводство. - 2000. - №4. - С. 15-16.

8. Тулинов, А.Г. Сравнительная оценка отечественных и зарубежных образцов ежи сборной в условиях северного региона / А. Г. Тулинов, Т. В. Косолапова // Вестн. НГАУ. - 2019. - №3 (52). - С. 67-73. https://doi.org/10.31677/20726724-2019-52-3-67-73

9. Уразова, Л.Д. Селекция ежи сборной в условиях таежной зоны Томской области / Л.Д. Уразова, О. В. Ложкина // Науч. жизнь. - 2012. - №3. - С. 18-24.

10. Уразова, Л.Д. Зимостойкость ежи сборной в экстремальных условиях таежной зоны / Л.Д. Уразова, О. В. Литвинчук // Науч. жизнь. - 2018. - № 10. - С. 64-76.

11. Тулинов, А. Г. Продуктивность образцов ежи сборной (Dactylis glomerata L.) в условиях Севера / А. Г. Тулинов, Т. В. Косолапова // Кормопроизводство. - 2018. - № 11. - С. 38-41.

12. Демина, М.И. Урожайность овсяницы тростниковой и ежи сборной на увлажненных местах при разном уровне азотного питания / М.И. Демина, А.В. Соловьев // Аграр. Россия. - 2012. - №3. - C. 2-4. https://doi. org/10.30906/1999-5636-2012-3-2-4

13. Лазарев, Н.Н. Влияние азотных удобрений на урожайность пастбищных травосмесей на основе райграса пастбищного, ежи сборной и клевера ползучего / Н.Н. Лазарев, Т. В. Костикова, А. И. Беленков // Плодородие. 2016. - № 3 (90). - C. 24-27.

14. Wiśniewska-Kadżajan, B. Concentrations of $\mathrm{K}, \mathrm{Mg}$ and $\mathrm{Na}$ and their ionic relations in Dactylis glomerata L. Biomass grown in soil with mushroom substrate and mineral fertilizers / B. Wiśniewska-Kadżajan, E. Malinowska, M. Misiak // Appl. Ecology a. Environmental Research. - 2017. - Vol. 15, N 3. - P. 1269-1278. https://doi.org/10.15666/aeer/1503_12691278

15. Tilvikiene, $V$. Effects of 5 years of digestate application on biomass production and quality of cocksfoot (Dactylis glomerata L.) / V. Tilvikienė, A. Šlepetienė, Ž. Kadžiulienė // Grass a. Forage Science. - 2018. - Vol. 73, N 1. - P. $206-217$. https://doi.org/10.1111/gfs.12306

16. Ежа сборная (Dactylis glomerata L.) / С.И. Костенко [и др.] // Основные виды и сорта кормовых культур. Итоги научной деятельности Центрального селекционного центра / Всерос. науч.-исслед. ин-т кормов. - М., 2015. - С. 187-190.

17. Корма Республики Татарстан: состав, питательность и использование : справочник / Л.П. Зарипова [и др.] ; Тат. науч.-исслед. ин-т сел. хоз-ва. - Изд. 3-е, перераб. и доп. - Казань : Фолиантъ, 2010. - 271 с.

18. Справочник по кормопроизводству / В. М. Косолапов [и др.] ; Всерос. науч.-исслед. ин-т кормов. - 5-е изд., перераб. и доп. - М. : Россельхозакадемия, 2014. - 717 с.

19. Система земледелия Республики Коми / Г. Т. Шморгунов [и др.]. - Сыктывкар : ГОУ ВО КРАГСиУ, 2017. - 225 с.

20. Using carbon dioxide for fodder conservation / A. F. Triandafilov [et al.] // J. of Pharmaceutical a. Research. - 2017. Vol. 9, N 5. - P. 728-731.

21. Бретшнайдер, С. Свойства газов и жидкостей: инженерные методы расчета : пер. с пол. / С. Бретшнайдер ; под ред. П.Г. Романкова. - М. ; Л. : Химия, 1966. - 536 с.

22. Мельников, С.В. Планирование эксперимента в исследованиях сельскохозяйственных процессов / С. В. Мельников, В.Р. Алешкин, П. М. Рощин. - 2-е изд., перераб. и доп. - Л. : Колос, 1980. - 168 с.

23. Москаленко, С. П. Теоретическое и практическое обоснование использования сенажа в мягкой упаковке в рационах крупного рогатого скота : дис. ... д-ра с.-х. наук : 06.02 .02 / С. П. Москаленко. - Саранск, 2006. - 323 л.

24. Тулинов, А.Г. Результаты оценки коллекционных образцов Dactylis glomerata L. в условиях Республики Коми / А.Г. Тулинов, Т.В. Косолапова, Е.А. Михайлова // Земледелие. - 2019. - №3. - С. 41-43. https://doi. org/10.24411/0044-3913-2019-10311

25. Таранов, Н.Г. Химическое консервирование кормов / Н.Г. Таранов. - 2-е изд., перераб. и доп. - М. : Колос, 1982. $-143 \mathrm{c}$

\section{References}

1. Khorkhin S.N. Mikrobiologicheskie osnovy konservirovaniya zelenykh kormov: uchebnoe posobie [The microbiological basics of conserving green feed: a tutorial]. St. Petersburg, Prospekt Nauki, 2017, 192 p. (in Russian).

2. Struzhkina T.M. Selektsionnaya tsennost' zarubezhnykh obraztsov ezhi sbornoi [Selective significance of the foreign samples of Dactylis glomerata L.]. Kormoproizvodstvo = Fodder Production, 2009, no. 6, pp. 22-25. (in Russian).

3. Naumova T. V., Emel'yanov A.N. Rezul'taty otsenki kollektsionnykh obraztsov ezhi sbornoi v usloviyakh Primorskogo kraya [The results of evaluating the collection accessions of Dactylis glomerata L. under the conditions of the Primorskiy Krai]. Vestnik Altaiskogo gosudarstvennogo agrarnogo universiteta = Bulletin of Altai State Agrarian University, 2015, no. 8(130), pp. 22-27. (in Russian). 
4. Chuvilina V.A. Preimushchestva khozyaistvenno poleznykh priznakov selektsionnogo nomera ezhi sbornoi SN-1/2 v predvaritel'nom sortoispytanii [Preliminary trial of cocksfoot genotype sn-1/2 as a carrier of economically important traits]. Kormoproizvodstvo = Fodder Production, 2018, no. 11, pp. 38-41. (in Russian).

5. Triandafilov A.F. Sposoby i tekhnicheskie sredstva povysheniya effektivnosti obrabotki sena khimicheskimi konservantami. Dis. kand. tekh. nauk [Methods and technical means of increasing the efficiency of hay treatment with chemical preservatives. Cand. tech. sci. diss.]. Leningrad-Pushkin, 1986. 156 p. (in Russian).

6. Lobanov A. Yu., Triandafilov A.F. Rezhimy i parametry tekhnologii obrabotki senazha uglekislym gazom v usloviyakh Respubliki Komi [Regimes and parameters of technology of silage processing with carbon dioxide in the Komi Republic]. Agrarnaya nauka Evro-Severo-Vostoka = Agricultural Science Euro-North-East, 2016, no. 4(53), pp. 75-80. (in Russian).

7. Zvereva G. K., Bogolyubova E.V. Ispol'zovanie ezhi sbornoi pri uluchshenii estestvennykh degradirovannykh pastbishch lesostepi [Using Dactylis glomerata L. to improve the natural degraded pastures of the forest-steppe]. Kormoproizvodstvo = Fodder Production, 2000, no. 4, pp. 15-16. (in Russian).

8. Tulinov A. G., Kosolapova T.V. Sravnitel'naya otsenka otechestvennykh i zarubezhnykh obraztsov ezhi sbornoi v usloviyakh severnogo regiona [Comparative assessment of national and foreign samples of cocksfoot grass in the Northern region]. Vestnik Novosibirskogo gosudarstvennogo agrarnogo universiteta = Bulletin of NSAU (Novosibirsk State Agrarian University), 2019, no. 3(52), pp. 67-73. doi: 10.31677/2072-6724-2019-52-3-67-73. (in Russian).

9. Urazova L. D., Lozhkina O. V. Selektsiya ezhi sbornoi v usloviyakh taezhnoi zony Tomskoi oblasti [Selection of the Dactylis glomerata L. in the taiga zone of the Tomsk region]. Nauchnaya zhizn' = Scientific Life, 2012, no. 3, pp. 18-24. (in Russian).

10. Urazova L. D., Litvinchuk O.V. Zimostoikost' ezhi sbornoi v ekstremal'nykh usloviyakh taezhnoi zony [Winter hardiness of the cocksfoot in the extreme conditions of the taiga zone]. Nauchnaya zhizn' = Scientific Life, 2018, no. 10, pp. 64-76. (in Russian).

11. Tulinov A. G., Kosolapova T. V. Produktivnost' obraztsov ezhi sbornoi (Dactylis glomerata L.) v usloviyakh Severa [Productivity of cocksfoot samples (Dactylis glomerata L.) in the North]. Kormoproizvodstvo = Fodder Production, 2018, no. 11, pp. 38-41. (in Russian).

12. Demina M. I., Solov'ev A. V. Urozhainost' ovsyanitsy trostnikovoi i ezhi sbornoi na uvlazhnennykh mestakh pri raznom urovne azotnogo pitaniya [The yield of tall fescue and cocksfoot in moist places at different levels of nitrogen nutrition]. Agrarnaya Rossiya = Agrarian Russia, 2012, no. 3, pp. 2-4. doi: 10.30906/1999-5636-2012-3-2-4. (in Russian).

13. Lazarev N. N., Kostikova T. V., Belenkov A.I. Vliyanie azotnykh udobrenii na urozhainost' pastbishchnykh travosmesei na osnove raigrasa pastbishchnogo, ezhi sbornoi i klevera polzuchego [Effect of nitrogen fertilizers on productivity of pasture grass mixtures composed of perennial ryegrass, cocksfoot, and white clover]. Plodorodie = «Plodorodie», 2016, no. 3(90), pp. 24-27. (in Russian).

14. Wiśniewska-Kadżajan B., Malinowska E., Misiak M. Concentrations of $\mathrm{K}, \mathrm{Mg}$ and $\mathrm{Na}$ and their ionic relations in Dactylis glomerata L. Biomass grown in soil with mushroom substrate and mineral fertilizers. Applied Ecology and Environmental Research, 2017, no. 15(3), pp. 1269-1278. doi: 10.15666/aeer/1503 12691278.

15. Tilvikienè V., Šlepetienė A., Kadžiulienė Ž. Effects of 5 years of digestate application on biomass production and quality of cocksfoot (Dactylis glomerata L.). Grass and Forage Science, 2018, no. 73(1), pp. 206-217. doi: 10.1111/gfs.12306.

16. Kostenko S. I., Kuleshov G. F., Klochkova V. S., Kostenko N. Yu. Ezha sbornaya (Dactylis glomerata L.) [Cocksfoot (Dactylis glomerata L.)]. Osnovnye vidy i sorta kormovykh kul'tur [The main types and varieties of feed crops]. Moscow, 2015, pp. 187-190. (in Russian).

17. Zaripova L. P., Gibadullina F. S., Shakirov Sh. K., Tagirov M. Sh., Nurtdinov M. G., Khazipov N. N., Bykova M. Yu., Gabdrakhmanov I. Kh., Shurkhno R. A., Lukmanov A. A. Korma Respubliki Tatarstan: sostav, pitatel'nost' i ispol'zovanie: Spravochnik [Feed of the Republic of Tatarstan: composition, nutrition and use: Reference]. Kazan, Foliant, 2010,272 p. (in Russian).

18. Kosolapov V. M., Trofimov I.A. Spravochnik po kormoproizvodstvu [Directory of feed production]. Moscow, Rossel'khozakademiya, 2014, 717 p. (in Russian).

19. Shmorgunov G. T., Kokovkina S. V., Tsvetkova Z. K., Oblizov A. V., Yudin A. A., Chebotarev N. T., Bulatova N. V., Belyaeva R. A., Triandafilov A. F., Blokh E. A., Makarovskii P. A., Shekhonin Yu. M., Khomchenko A. A., Kolegov N. V., Ermolina V. I., Kosolapova T. V., Karakchieva E. F., Tulinov A. G., Konkin P. I., Pelevina N. I., Shestopalova N. S., Babela A. V., Semenchin S. I., Romanov G. G., Ortyakova T. V., Lobanov A. Yu., Regorchuk N. V., Shershunova O. N., Popov D. A. Sistema zemledeliya Respubliki Komi [The farming system of the Komi Republic]. Syktyvkar, GOU VO KRAGSiU, 2017,225 p. (in Russian).

20. Triandafilov A. F., Lobanov A. Y., Tulinov A. G., Shlyk M. Y. Using carbon dioxide for fodder conservation. Journal of Pharmaceutical and Research, 2017, no. 9(5), pp. 728-731.

21. Bretshnaider S. Svoistva gazov i zhidkostei [Properties of gases and liquids]. Moscow, Khimiya, 1966,536 p. (in Russian).

22. Mel'nikov S. V., Aleshkin V. R., Roshchin P.M. Planirovanie eksperimenta v issledovaniyakh sel'skokhozyaistvennykh protsessov [Planning an experiment in research of agricultural processes]. Leningrad, Kolos, 1980, 168 p. (in Russian).

23. Moskalenko S.P. Teoreticheskoe i prakticheskoe obosnovanie ispol'zovaniya senazha v myagkoi upakovke v ratsionakh krupnogo rogatogo skota. Dis. dokt. sel'khoz. nauk [Theoretical and practical rationale for the use of haylage in soft packaging in cattle diets. Dr. agric. sci. diss.]. Saransk, 2006. 323 p. (in Russian).

24. Tulinov A. G., Kosolapova T. V., Mikhailova E. A. Rezul'taty otsenki kollektsionnykh obraztsov Dactylis glomera$t a \mathrm{~L} . \mathrm{v}$ usloviyakh Respubliki Komi [Results of the evaluation of collection samples of Dactylis glomerata L. under conditions of the Komi Republic]. Zemledelie = «Zemledelije», 2019, no. 3, pp. 41-43. doi: 10.24411/0044-3913-2019-10311. (in Russian).

25. Taranov N. G. Khimicheskoe konservirovanie kormov [Chemical conservation of feed]. Moscow, Kolos, 143 p. (in Russian). 


\section{Информация об авторах}

Тулинов Алексей Геннадьевич - кандидат с.-х. наук, научный сотрудник отдела сельскохозяйственной геномики, Институт агробиотехнологий ФИЦ Коми НЦ УрО РАН (ул. Ручейная, д. 27, 167023 Сыктывкар, Республика Коми, Российская Федерация). E-mail: toolalgen@mail. ru. http://orcid.org/0000-0002-7184-6113

Лобанов Александр Юрьевич - младший научный сотрудник отдела сельскохозяйственной геномики, Институт агробиотехнологий ФИЦ Коми НЦ УрО РАН (ул. Ручейная, д. 27, 167023 Сыктывкар, Республика Коми, Российская Федерация). http://orcid.org/0000-00031653-2987

\section{Information about the authors}

Aleksei G. Tulinov - Ph.D. (Agricultural). Institute of Agrobiotechnology Federal Research Center Komi Scientific Center Ural Branch of the Russian Academy of Sciences (27 Rucheinaya Str., Syktyvkar 167023, Komi Republic, Russian Federation). E-mail: toolalgen@mail.ru. http://orcid. org/0000-0002-7184-6113

Aleksander Yu. Lobanov-Institute of Agrobiotechnology Federal Research Center Komi Scientific Center Ural Branch of the Russian Academy of Sciences (27, Rucheinaya Srt., Syktyvkar 167023, Komi Republic, Russian Federation). http://orcid.org/ 0000-0003-1653-2987 